InnOvaciOnes de NegOciOs 18(35):

(c) 2021 UANL, Impreso en México (ISSN: 2007-1191)

Recepción: 6 de octubre 2020 Aceptación: 7 de enero 2021

\title{
Decisiones familiares y teoría de juegos: micro emprendimiento y género (Family decisions and game theory: micro-entrepreneurship and gender)
}

\author{
Eduardo Velázquez Juárez ${ }^{1}$ \& Alejandra Elizabeth Urbiola Solís ${ }^{2}$ \\ Universidad Autónoma de Querétaro \\ vjlalo@gmail.com 1; alex-urbiola@hotmail.com ${ }^{2}$
}

\begin{abstract}
This article is intending to reproduce and associate through a game theory model the process of credit access in family-micro-entrepreneurship. For this purpose, is used a signaling dynamic game with incomplete information and is shown the participation of the family by gender, opportunity costs, and an alternative to the domestic job. The findings show that in families there are some aggrupation and separation equilibria that coincide with the reviewed theory. Some limitations are the need of display with more precision the model implications. This study is valuable because reflects the non-observable decision making in entrepreneurship through the construction of equations. It is concluded that there are preferences for male gender over female gender in the entrepreneurship process due to existing social-character limitations that affect women in their entrepreneur roll.
\end{abstract}

Key words: Entrepreneurship, gender, game theory.

JEL: C70, L26, J16.

Resumen: Este artículo busca reproducir y vincular mediante un modelo de teoría de juegos el proceso de decisiones familiares en micro emprendimientos a partir del género. Se desarrolla un juego dinámico de señalización con información incompleta donde se muestra la participación de la familia por género, los costos de oportunidad y una alternativa al trabajo doméstico. Los hallazgos destacan que las familias tienen algunos equilibrios de agrupación y separación similares a la teoría. Limitaciones: El estudio se limita por la necesidad de plantear con mayor precisión las implicaciones y pagos mediante evidencia empírica cuantificable. Es valioso este estudio por reflejar las

\section{Decisiones familiares y teoría de juegos}


decisiones no observables directamente en el emprendimiento con a través de la construcción de ecuaciones. Se concluye que existe una preferencia por el género masculino sobre la mujer en el proceso de emprendimiento a raíz de limitaciones de carácter social que afectan su rol de empresaria.

Palabras clave: Teoría de Juegos; Emprendimiento, Género.

\section{Introducción}

Las decisiones acerca del emprendimiento familiar son un fenómeno que subyace en las manifestaciones empíricas del propio emprendimiento, dicho fenómeno cuenta con patrones y esquemas específicos de comportamiento entre los miembros de una familia y que pueden parecer independientes de la condición de género del empresario, generando la interrogativa de ¿cuál es la relación entre las decisiones de emprendimiento familiar con la condición de género del emprendedor? ¿cómo se negocian los roles familiares en un emprendimiento familiar de acuerdo con el género? ¿De qué manera el género se asocia con otras variables involucradas en el proceso de emprendimiento familiar?.

Partiendo de las interrogatorias que dan origen al estudio, se hace mención que hay variables del proceso del emprendimiento como el acceso al crédito y el costo del dinero que son en ocasiones una barrera estructural para el desarrollo de las pequeñas empresas familiares y que a su vez de acuerdo con el género del emprendedor marca diferencias sustanciales. Por ello, este artículo tiene el objetivo de demostrar la relación de las decisiones del emprendimiento con la condición del género a través del planteamiento de ecuaciones específicas que asocian las decisiones familiares con los beneficios potenciales de cada una a través de la modelación con la teoría de juegos usando un juego de señalización con información incompleta.

En dicho desarrollo se esbozan los procesos de decisiones familiares y cómo se involucran las limitantes del sistema financiero. Con ello, es posible introducir la variable transversal de género para comprender la evaluación sobre una posible actividad empresarial; los potenciales beneficios, expresados en términos de flujos de efectivo, y las decisiones de los emprendedores. Asimismo, es posible mostrar la reacción de las instituciones financieras ante las condiciones que se presentan según el miembro de la

Velázquez Juárez, E. \& Urbiola Solís, A. 
familia que solicita un préstamo. Sin embargo, el modelo presenta limitaciones inherentes dada la necesidad de mayor vinculación de los supuestos planteados en el modelo con las manifestaciones empíricas de las decisiones considerando las creencias y valores de los actores involucrados respecto de los pagos, incentivos y costos planteados.

Existen manifestaciones que reflejan la poca capacidad competitiva en el mercado por parte de las empresas pequeñas, en ocasiones por problemas estructurales en relación al acceso y a las condiciones del crédito (tipo, costo, cobertura, etc.) y en otras, debido a factores socioculturales que replican las desigualdades de género (Saavedra, Tapia, y Aguilar, 2014) a pesar de que se reconoce que estas empresas contribuyen a generar empleos (De la Rosa, 2010). Esta investigación se conceptualiza el género como una categoría sociocultural según Lagarde (1996). De acuerdo con Burin y Meler (2010) y Burin (2012) los procesos de socialización del género encuentran sus orígenes en contextos históricos y sociales que delimitan ciertos sistemas simbólicos que se reproduce en un sistema de sexo-género dando origen a experiencias sociales que en el juego presentado en este artículo han sido planteadas. De esa forma, la psicosexualidad del sujeto reproduce un sistema sexo-genéro (Rubin, 2013) que funciona como un dispositivo de regulación social (Rubin, 1986). En el modelo propuesto en este artículo se plantean dos escenarios antagónicos que concentran la legitimidad, originalidad y valor de esta contribución al campo de las ciencias económicas en virtud de la transformación de consideraciones tácitas a explicitas del proceso de emprendimiento familiar; logrado a través del modelado teórico-empírico, la construcción de ecuaciones e incorporación de dichos elementos en un proceso empresarial y familiar con consideraciones un campo microeconómico como la teoría de juegos.

Las pymes, el género y su problematización

El estudio de las Mipymes en México ha sido abordado con diferentes perspectivas metodológicas y ángulos de análisis, enfocados en la búsqueda de posibles respuestas sobre el desempeño e incertidumbre que acompaña a este tipo de empresas. Se reconoce que el análisis debe realizarse desde la complejidad y que involucra diferentes variables, en ese sentido es

\section{Decisiones familiares y teoría de juegos}


multifactorial. De acuerdo De la Rosa (2010) son necesarios nuevos estudios, con nuevos enfoques de análisis sobre sus especificidades y particularidades, con la intención de aproximarse al conocimiento de esta realidad que enfrenta dicho sector de empresas de amplia relevancia para la economía mexicana. Este estudio presenta una propuesta que incorpora la transdisciplina a través del género como una variable que demanda y requiere con cada vez más frecuencia ser explicada en los fenómenos cotidianos.

Algunos de los problemas que experimentan las Mipymes en México varían de una empresa a otra, de un sector a otro, de una región a otra, de un país a otro e inclusive de una década a otra. En este contexto cambiante se expone a las Mipymes a un alto riesgo de continuidad y permanencia (De la Rosa, Rivera y Marín, 2015). En este sentido se considera importante mencionar que, de cada 100 Microempresas creadas en México, 90 no logran llegar a los dos años de permanencia, lo que se traduce en un alto índice de fracaso empresarial en corto tiempo (Chávez, 2014). La baja permanencia se relaciona con la alta tasa de rotación, las condiciones de competencia en los mercados, los altos costos de transacción, y la falta de innovación y estrategias mercadológicas, entre otros. Pese a considerar estas barreras estructurales que limitan a las pequeñas empresas, para este articulo se considera que a nivel de empresa familiar hay espacios de negociación con base en el género, en muchas veces de carácter tácito más que explicito, y que plantean quién de los integrantes de la familia es quien desempeñará la función de empresario como pilar de sostenimiento familiar y empresarial, por lo que éste articulo se concentra en entender dichos espacios.

Respecto de su importancia social, manifiesta Rodríguez (1996), que la Mipyme, ayuda a incorporar la fuerza de trabajo al sector manufacturero, comercio o servicios, lo que implica que la pequeña empresa contribuye a que un sector desprotegido de la sociedad, logre incrementar y mejorar sus condiciones de vida, teniendo un impacto positivo en la demanda agregada. Por otro lado, en estas empresas es posible capacitar a la mano de obra y asumir los costos de una educación técnica formal. Estas empresas también se construyen en redes de apoyo entre parientes y amigos quienes, en conjunto, a partir de una idea, emprenden una actividad económica de manera organizada y en pequeña escala. Bajo este enfoque, las microempresas

funcionan como un mecanismo de captación de ahorros que son encauzados

Velázquez Juárez, E. \& Urbiola Solís, A. 
hacía la producción que de otra manera permanecerían ociosos (Rodríguez, 1996). A continuación se extienden los principios teóricos que han derivado en la participación femenina y no únicamente masculina en las actividades laborales independientes con un rastreo no sólo sociohistórico, sino también económico, sustentando así los supuestos de asociación de negociación y género en los emprendimientos familiares.

\section{La mujer, el mercado laboral y el emprendimiento en México}

Para Pérez (2012) la actividad productiva en México determinó el modo en el cual se presentó la inserción laboral femenina. Al respecto, se puede rastrear desde el modelo de desarrollo de sustitución de importaciones, orientado hacia el mercado interno en el siglo pasado, una inserción gradual de la fuerza de trabajo femenina sostenida por el gran crecimiento económico que experimentó México y que permitió el incremento sostenido de percepciones salariales y prestaciones sociales -incluida la educación- y que sembró las bases para lograr una historia laboral definida por los acontecimientos económicos que presenció el país. Si bien es cierto que existieron múltiples procesos de exclusión de los mercados laborales para las mujeres, los procesos de educación y desarrollo de ciudades intermedias sembraron las bases para una futura inserción en los mercados laborales (Rendón y Salas, 2000). Durante el periodo de desarrollo estabilizador, fue posible que muchos hombres ocuparan puestos de trabajo estables con sueldos reales altos debido al control inflacionario durante el periodo y las mujeres cuya esfera de reproducción doméstica era el hogar y los hijos, pudieran comenzar a plantearse cambios en los roles tradicionales (Rendón, 2004).

Durante la década de los setenta, la inestabilidad económica determinó que las condiciones del mercado laboral presentaran sobreoferta de mano de obra, bajos salarios, baja productividad, aumento del nivel inflacionario y crecimiento del producto interno bruto negativo. Paradójicamente, se registró una inserción de la mano de obra femenina en el sector terciario, específicamente en las actividades comerciales (Pérez, 2012). La participación femenina en el mercado laboral se vio incentivada también por los cambios socioculturales: el acceso a los anticonceptivos y la disminución en el número

\section{Decisiones familiares y teoría de juegos}


de hijos; el aumento de la edad promedio de vida de hombres y mujeres; el creciente número de familias con jefatura monoparental, entre otros (Ariza y De Oliveira, 2004; Tuirán, 2002).

A partir de la crisis de 1982, se incorporaron cada vez más los miembros del hogar a las actividades productivas, incrementando la participación femenina en el empleo (Pérez, 2012). En este aspecto, indican que existen tres procesos laborales particulares de la década de los ochenta en México, que son: el crecimiento de las actividades en pequeña escala, la terciarización y la feminización de la fuerza del trabajo. De la O y Guadarrama (2006) afirman que tres eventos de especial importancia lo hicieron posible. En primer lugar, el cambio el cambio del modelo económico de los años ochenta y la modificación de las regulaciones laborales. Segundo, la entrada de las mujeres a la fuerza de trabajo en los años noventa dadas las condiciones de desempleo y salarios bajos ocasionados por políticas de ajuste y por último los ajustes a la reducción de costos laborales a través de la subcontratación para incrementar la productividad y la competitividad.

Dado el contexto histórico descrito con anterioridad, los empleos de baja productividad y del sector informal presentaron una feminización importante, entre dichas actividades se encuentran los trabajos por cuenta propia y la iniciativa microempresarial en los años de crisis (Ariza y De Oliveira, 2004; De la 0 \& Guadarrama, 2006). Durante la década de los noventa, se presentó nuevamente un periodo de crisis que sumado al modelo neoliberal precarizó el empleo de nueva cuenta, afectando a la fuerza laboral femenina asalariada y no asalariada, y cuya consecuencia fue la paulatina incorporación de mujeres en actividades productivas mediadas por un salario (Rendón y Salas, 2000). La crisis económica y el subsecuente estancamiento disminuyó el crecimiento de los sectores primario y secundario; las actividades del sector terciario retomaron relevancia en la generación de empleos, aumentando los micronegocios, el ambulantaje y los servicios personales ocupados preponderantemente por las mujeres (Rendón y Salas, 2000).

El desenvolvimiento de la producción del país, medida en términos de producción real se encuentra expuesto gráficamente en la figura 1. en donde se pueden identificar las variaciones del producto interno bruto entre el modelo de desarrollo estabilizador y entrada del modelo neoliberal de apertura económica. 
Figura 1. Producto interno bruto mexicano en el periodo de 1961-1991

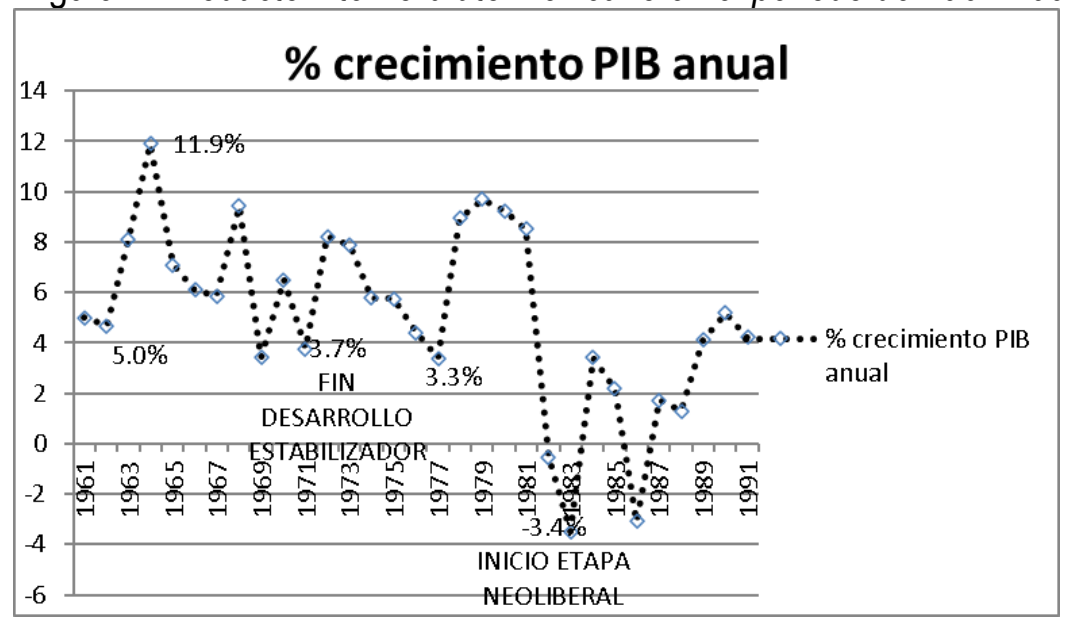

Fuente: Elaboración propia a partir de Banco Mundial (2019).

Es necesario remarcar que para Pérez (2012) la condición laboral para las mujeres continúa siendo lejana al ideal de igualdad de género. Pues en general, tienden a ocupar empleos que reproducen las etiquetas de género en la esfera pública. Existe también una división del trabajo en relación con el estado civil; para las mujeres solteras los empleos pueden ser en la industria donde existe una mayor exigencia en relación a la jornada de trabajo y las entradas y salidas, mientras que, para las mujeres casadas, existe la tendencia a ocuparse en actividades de autoempleo ya que les permiten organizar sus horarios y atender a sus familias.

Inclusive, aunque la exclusión extra doméstica se ha atenuado, las condiciones de precariedad subsisten, así como la discriminación por género y la doble jornada en el hogar debido a que la inserción laboral no vino acompañada por un cambio en los roles de género para el varón. (Ariza y De Oliveira (2004) y Rendón (2004) En este aspecto, existen dos elementos que incentivan al género masculino y femenino al emprendimiento, en primer lugar los factores de inducción, entendidos como la necesidad de generar o complementar el ingreso dada la falta de oportunidades en el mercado laboral y en segundo lugar, los factores de atracción dada la detección de una oportunidad comercial específica, el deseo de lograr mayor flexibilidad laboral, la realización de una vocación vital o la capitalización comercial. En este

\section{Decisiones familiares y teoría de juegos}


aspecto, ambos factores muestran la reproducción social de un imaginario colectivo y de los sistemas simbólicos dominantes sobre el "deber ser" por género (Banco Mundial, 2010). Estos factores inciden en forma diferente en el hombre y en la mujer para convertirse en empresario o empresaria, pues en el caso de las mujeres se vincula con las configuraciones de cuidado en el hogar, así como un sustento de carácter secundario en las actividades económicas familiares. En el caso de los hombres, el papel de proveedor en la reconfiguración de una nueva masculinidad en proceso de cambio no parece modificarse.

El Banco Mundial (2010), indica que existen factores que pueden incentivar la participación femenina en actividades empresariales: una mayor educación, el entorno familiar, el acceso al crédito. La riqueza familiar influye inversamente en las posibilidades de que una mujer se convierta en empresaria, mientras que la existencia de más mujeres adultas en una familia resulta un factor importante para el inicio de actividades empresariales, sin embargo, en el caso de los hombres no se presenta la misma condición. Estas diferencias están dadas en razón de que la existencia de más mujeres en el espacio del hogar refuerza las capacidades de distribución y apoyo de actividades domésticas, otorgándoles mayor libertad para ejercer actividades empresariales. Por otro lado, las motivaciones de emprendimiento se ven reducidas en la medida de mayor existencia de riqueza familiar, ya que el comportamiento como proveedor principal o secundario de las mujeres se ve influenciado a ser el sostén secundario en términos económicos cuando se trata de una familia nuclear, aunque esta condición sin duda varía en la medida que la mujer se encuentre casada, soltera con hijos o soltera sin hijos.

Diferencias de género en el acceso al crédito y al emprendimiento

El acceso al crédito es uno de los factores en el desarrollo de negocios que puede llegar a representar importantes retos para las pequeñas empresas y más aún cuando en ello se involucra el género y la familia (Rodríguez, 1998). Este reto se agudiza considerando las desigualdades de género existentes al momento de desarrollar una iniciativa empresarial que a su vez requiere de financiamiento para su existencia, ya que de acuerdo con la CEPAL (2004) existen diversos factores que se manifiestan en la desigualdad para la mujer,

Velázquez Juárez, E. \& Urbiola Solís, A. 
respecto del varón. En primer lugar, discuten el papel femenino en actividades asignadas socialmente como necesarias, generalmente relacionadas con la atención familiar que a su vez se relaciona con la condición de ser madre; de esta manera se vincula una condición biológica con una social y a esta última se le vuelve algo natural; esta condición orilla a la mujer a permanecer en la esfera privada y en actividades ligadas con el cuidado y la maternidad, limitando su desempeño en actividades de emprendimiento. No obstante, indica Sadik (1989) que pese a que las actividades domésticas discutidas anteriormente, no generan valor como una mercancía intercambiable en un mercado competido, contribuyen al desarrollo de las actividades -creativas y de salud- de los demás integrantes de la familia y en condiciones de crisis, han impulsado el desarrollo de micro emprendimientos.

Por otro lado, la CONDUSEF (s/f) indica que la gran mayoría de microcréditos son destinados a mujeres, existe una política más laxa por género debido a que las mujeres administran mejor los recursos financieros en relación con los varones, la razón se encuentra en los roles socialmente asignados -ama de casa y madre de familia-y las condiciones económicas en las que se encuentre la familia. Cuando una mujer está al frente como principal o único proveedor, en familia monoparental, se reconoce un mejor desempeño financiero. Esto hace posible que el dinero obtenido como utilidad sea aplicado en el bienestar familiar además de que el empoderamiento permite desarrollar sus capacidades permitiendo obtener beneficios intrapersonales y lograr mayor equidad en el hogar, trabajo y comunidad. Tras la obtención de un crédito indica la CONDUSEF, las mujeres pueden obtener beneficios económicos adicionales concebidos como un aumento en el ingreso de los hogares, la acumulación de activos, la superación de condiciones de pobreza y la protección frente al riesgo del contexto.

Es común para ambos géneros, que las instituciones de crédito en el proceso de asignación de crédito pueden solicitar información como las pruebas de identidad de la empresa, los niveles de ingresos, las características del negocio, la información sobre deudas existentes y las garantías físicas como tierras, inmuebles, equipos y efectivo. En este sentido, bancos como Compartamos, Programas de Gobierno Federal como Mujer emprende y Nacional Financiera a través de la Banca de Segundo Piso indican condiciones de crédito favorables para las mujeres tanto en tasas de interés, como en

\section{Decisiones familiares y teoría de juegos}


monto asignado y una reducción considerable de las garantías que se evalúa en función del monto crediticio, pudiendo ser nula en montos próximos a los 500,000 pesos mexicanos (Secretaría de Economía, 2017).

Beneficios e implicaciones del emprendimiento desde una perspectiva de género

En las mujeres, el efecto de la aplicación de recursos crediticios en actividades productivas juega un papel importante, pues dadas las desigualdades que experimentan permiten desarrollar una serie de beneficios intrapersonales, tales como el desarrollo de una identidad propia al reconocer sus capacidades y limitaciones así como el desarrollo de autoestima y autonomía económica tras la toma de decisiones empresariales que a su vez, repercute en los derechos económicos y sociales que le son conferidos tras el poder obtenido dada la iniciativa empresarial (CEPAL, 2004).

Sin embargo, también existen implicaciones interpretadas como mayores cargas de trabajo y mayores niveles de estrés al tener que enfrentar los pagos del crédito y asumir la competencia en el libre mercado, complicando así la administración del tiempo personal y familiar, provocando a su vez potenciales adversidades en las relaciones con hijos o familiares que pudieran depender del grado de atención por parte de la mujer emprendedora (Mayoux, 2000 y Organización Internacional del Trabajo, 2001).

En este sentido indica la CEPAL (2004) que el acceso al crédito a las mujeres hasta el momento no permite justificar los potenciales efectos adversos que la actividad empresarial pueda tener, por lo que resulta estratégico y recomendable, en primer lugar comprender el fenómeno de desigualdad en emprendimiento y toma de decisiones empresariales por parte de las mujeres y en segunda instancia generar políticas públicas integrales en términos de prestatario y prestamista, que permitan incentivar las responsabilidades compartidas en pareja y sociedad procurando matizar los efectos adversos que pueda generar el emprendimiento femenino.

Dadas las condiciones anteriormente expuestas es que se decide abordar este fenómeno de la desigualdad de género en el emprendimiento y crédito desde la perspectiva de la teoría de juegos. A través de un modelo de juegos dinámico se presentan las opciones para los actores partiendo del 
modelo de juegos con información incompleta el cual se caracteriza por que las decisiones se realizan de un modo secuencial y algún jugador posee información privada, impidiendo la información perfecta para ambas partes. En este modelo de juegos, las acciones escogidas por el jugador que juega primero sirven para enviar señales y el que juega después cuenta con información adicional para tomar decisiones (Gibbons, 1994). De esta manera, participan dos actores principales que son el emprendedor mujer o varón; mientras que las instituciones de crédito, representadas como bancos comerciales, el mercado, la sociedad y la familia son actores que participan de modo indirecto e implican en su debido momento las distribuciones de probabilidad y las funciones de pagos generadas en el juego.

\section{Metodología}

\section{El modelo y supuestos planteados para el modelo}

El modelo propuesto, busca ejemplificar el modo en el que se desenvuelve el género en el emprendimiento y el género dentro de una familia mexicana, estructurada por un padre, una madre y un número indeterminado de dependientes. Se excluyen en el modelo las familias monoparentales y no se determina si la familia es ensamblada o extensa, ya que se parte del modelo de crédito analizado por la CONDUSEF. Partiendo de estas premisas, se establece un juego en el que la madre o el padre desean optar por una actividad de emprendimiento con el afán de generar riqueza familiar, en donde la familia puede optar por elegir quién dará inicio a la actividad empresarial con una probabilidad dada, mientras que la institución crediticia no conoce con certeza los flujos de efectivo futuros que la iniciativa empresarial puede entregar para pagar el principal e intereses, solamente conoce el supuesto de que la mujer resulta ser mejor pagadora que el hombre dentro de la iniciativa empresarial. El juego se desarrolla partiendo de la elección de un tipo dada por la probabilidad de obtener flujos de efectivo suficientes para pagar el financiamiento crediticio, el jugador que decide emprender envía un mensaje a la institución crediticia que a su vez valorará un conjunto posible de respuestas, permitiendo encontrar así un conjunto de equilibrios para un juego dinámico con información incompleta.

\section{Decisiones familiares y teoría de juegos}


Una de las limitaciones del modelo que es necesario reconocer a priori tiene que ver con la necesidad de mejorar y detallar precisión con la que se sustentan los pagos determinados en las implicaciones del modelo. Por lo tanto, aunque las implicaciones del modelo parten de la observación directa y la revisión teórica, es necesario profundizar esta investigación desde un enfoque sobre la precisión de las creencias, intereses, expectativas y necesidades que sustenten ambos géneros a través de distintos métodos y técnicas de investigación (Yurén, 2004). Es importante mencionar que uno de los alcances metodológicos de este artículo radica en proponer una alternativa para abordar fenómenos complejos en su comprensión para dimensiones como el género, la familia y la economía.

Para efectos del desarrollo del modelo, tal como se ha mencionado con anterioridad, se considerará un juego dinámico con información incompleta el cual se desarrolla bajo el esquema de un juego de señalización Gibbons (1994)

en el cual se definen las siguientes consideraciones:

1. El azar elige a un tipo $t$ del conjunto de $t$ factibles para el emprendedor donde $t=$ (Flujos de efectivo empresariales suficientes para pagar el crédito solicitado; Flujos de efectivo insuficientes para pagar el crédito solicitado).

2. que asigna al emisor siguiendo una distribución de probabilidad $p_{(\mathrm{t}),}$ en donde $p_{(\mathrm{ti})}>0$ y $p_{(\mathrm{t} 1)+\ldots+} p_{(\mathrm{tn})}=1$.

En esta consideración, se establece el supuesto de que el potencial emprendedor tiene una idea preliminar para la iniciativa empresarial, en donde el emprendedor estima financieramente la posibilidad de pagar flujos de efectivo para poder cubrir con las amortizaciones periódicas de la deuda contratada. Sin embargo, cada uno de los tipos para este juego, se definen a partir de una probabilidad dada, en la que inciden participantes como el mercado, la organización interna del negocio emprendido, las apreciaciones sociales con respecto al negocio y las relaciones familiares que en su conjunto modifican las probabilidades de generar los suficientes flujos de efectivo del negocio para pagar el crédito solicitado. Por lo tanto, el emisor no tiene la posibilidad de elegir con plena certeza cuál será su tipo. 
3. El emisor (Emprendedor en potencia) observa un $t_{(i)}$ y elige un mensaje $m_{(i)}$ del conjunto de mensajes factibles $m=$ (Emprendedor de género masculino; Emprendedor de género femenino)

Para esta consideración, una vez elegido el tipo para el emisor, éste elige un mensaje que hará llegar al receptor (banco), el cual consiste en comunicar el género que decidirá emprender la iniciativa empresarial y por lo tanto de responsabilizarse al contratar la deuda bancaria y en su debido caso, recibir los pagos correspondientes que se describen a continuación.

4. El receptor (Institución de crédito) observa un $m_{j}$ pero no un $t_{j}$ y elije a continuación $a_{k}$ del conjunto de acciones $A=$ (Otorgar el crédito, no otorgar el crédito)

En esta consideración, se proponen los supuestos de que el receptor (banco) únicamente obtiene la información relativa al género que está contratando la deuda, en la cual también tiene información relativa a las estimaciones de los flujos de efectivo, empero ninguno de los dos participantes del juego tiene la certeza sobre cuál será el tipo elegido probabilísticamente, pese a que existan tendencias previas desfavorables para el microemprendedor familiar. Dentro de esta consideración el banco contempla que, en igualdad de condiciones de flujos de efectivo desfavorables, la mujer tiende a ser mejor pagadora que el hombre. También, es importante considerar en este supuesto que, pese a condiciones desfavorables en el negocio, la mujer tiene mayores incentivos familiares para buscar reestructurar las estrategias de negocio y buscar cubrir con las amortizaciones del financiamiento.

5. Las ganancias dadas vienen en función de $U_{\text {EMPRENDEDORFAMLLIAR }}\left(\mathrm{t}_{\mathrm{i}} \mathrm{m}_{\mathrm{j}}, \mathrm{a}_{\mathrm{k}}\right)$ y U UNSTITUCIONCRÉDITO $\left(\mathrm{t}_{\mathrm{i}}, \mathrm{m}_{\mathrm{j}}, \mathrm{a}_{\mathrm{k}}\right)$

En esta consideración, se toman en cuenta los pagos dados para el emprendedor y para el banco, en cada una de ellas se toman las siguientes implicaciones:

- El modelo supone que la iniciativa empresarial femenina es originada de la actividad doméstica que considera CEPAL (2004) y que sus costos de oportunidad al rechazar la oportunidad de emprendimiento es el trabajo doméstico no valorizado que enuncia Sadik (1989).

\section{Decisiones familiares y teoría de juegos}


- El modelo supone también que, dado que la mujer representa un mejor sujeto de crédito para las instituciones de un crédito que un hombre, entonces la exigencia de garantías para el modelo son $\mathbf{G}_{\mathbf{M}}<\mathbf{G}_{\mathrm{H}}$ y que $\mathbf{G}_{\mathrm{H}}>\mathbf{W}_{\mathbf{H}}$

- Se supone para este modelo que, de acuerdo con la postura de género, para la mujer siempre será más importante el bienestar integral de la familia que los beneficios económicos del emprendimiento $F>E_{M}$

- Siendo que:

$\mathrm{F}=$ Beneficios familiares por la atención de la madre (Sadik, 1989)

$E_{M}=$ Beneficios económicos por iniciativa empresarial de la mujer

- Siempre que la mujer decida emprender la iniciativa empresarial con un y obtenga el crédito para ejecutarlo se obtendrán $E_{M}>0, S>0, C F=-F\left(E_{M}\right)$, $\mathbf{G}=0$, y $\mathrm{IP}_{\mathrm{M}}=\mathrm{E}_{\mathrm{M}}>\mathbf{0}$.

- Siendo que:

$E_{M}=$ Beneficios económicos por iniciativa empresarial de la mujer

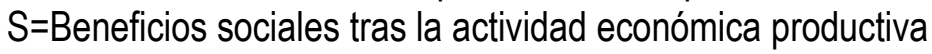

$\mathrm{CF}=$ Costos potenciales familiares tras el exceso de actividad empresarial que está en función del grado de beneficios económicos, representa un supuesto fuerte, sin embargo, establece una relación lineal entre la cantidad de beneficios económicos empresariales dado un trabajo aplicado y el grado de descuido en algún elemento familiar.

$\mathrm{IP}_{\mathrm{M}}=$ Beneficios intrapersonales femeninos tras el empoderamiento empresarial, los cuales suponen fuertemente una relación lineal con $\mathrm{E}_{\mathrm{M}}$.

$\mathrm{G}=$ Garantías solicitadas para la obtención del crédito

- Siempre que el banco entregue un crédito con probabilidad de ser pagado obtendrá entonces un pago por intereses dado $U_{\mathbb{B}}>0$.

- Cuando el banco entregue un crédito en condiciones favorables, sin importar el mensaje del emisor, recibirá un pago adicional de $\mathbf{S}>\mathbf{0}$ en función de los beneficios sociales que genera la iniciativa empresarial y que le son trasladados como consecuencia.

- Siempre que el hombre decida emprender la iniciativa empresarial y obtenga el crédito obtendrá $\mathbf{E}_{\boldsymbol{H}}>\mathbf{0}, \mathbf{S}>\mathbf{0}$ y $\mathbf{G}_{\mathrm{H}}$.

- Siendo que:

$\mathrm{E}_{\mathrm{H}}=$ Beneficios económicos del hombre dada la iniciativa empresarial

$S=$ Beneficios sociales tras la actividad económica productiva 
$G_{H}=$ Garantías exigidas por la institución de crédito al hombre (Hipotecaria)

- Pero siempre que no se obtenga ningún crédito y no se desarrolle la iniciativa empresarial, los pagos para el hombre y la mujer serán $\mathbf{W}_{\mathrm{H}}>0<\mathbf{W}_{\mathbf{M}}$, siendo asi $F\left(E_{M}\right)=W_{M}>0$

- Siendo que:

$W_{H}=$ Salario remunerado percibido por el hombre

$\mathrm{W}_{\mathrm{M}}=$ Salario obtenido por actividades domésticas y potencialización productiva familiar (Sadik, 1989).

Dadas las consideraciones anteriores, es posible observar que una vez establecidos los pagos de los jugadores y los supuestos de racionalidad para este modelo, se puede dar explicación a las dificultades de ejercer la actividad de emprendimiento para una mujer de una familia biparental, respecto de un hombre y que en gran parte el acceso al crédito, para ambos géneros está definida por una probabilidad ex ante en la que se define la probabilidad de que la iniciativa empresarial genere los flujos de efectivo suficientes para el pago del crédito.

En el modelo se puntualiza el carácter exógeno para el emprendimiento y acceso al crédito según una perspectiva de género, el cual difiere en cada uno de los intervalos en los que el banco decidirá si entregar el crédito o no al emprendedor, tratando de esta manera de explicar las dificultades del acceso al crédito para la mujer a partir de los equilibrios correspondientes. Para la estructuración del modelo se considerará siempre que sea posible la racionalidad bayesiana.

\section{Resultados}

El juego presentado, pone en relación a dos participantes, como emisor y tipo a una familia con la consideración previa de emprender un negocio, pero con la posibilidad de elegir entre el padre y la madre, para emprenderlo y solicitar un crédito ante la institución financiera.

En una primera instancia y para cumplir con el primer requisito de los juegos de señalización de Gibbons (1994) después de que la familia ha enviado el mensaje acerca de si la madre o el padre solicitarán el crédito para emprender, el banco debe formarse una conjetura acerca del tipo de respuesta

\section{Decisiones familiares y teoría de juegos}


esperada por el que pide el préstamo (si cuentan con flujo de efectivo favorable o desfavorable para pagar el crédito) que han enviado a través del mensaje. Teniendo en cuenta el mensaje de la familia con ánimos de emprender y las conjeturas del banco respecto de los flujos de efectivo del proyecto de negocios, es que inmediatamente se caracteriza la acción óptima del banco, llevando el juego a cumplir su segundo requisito.

Como segundo requisito, en un juego de señalización, el banco, buscará de acuerdo con cada mensaje obtenido, maximizar la utilidad esperada dada sus conjeturas respecto de los flujos de efectivo favorables o desfavorables para el proyecto empresarial de la familia. Mientras que también, la familia para cada tipo, debe buscar maximizar su utilidad dada la estrategia optada por el banco.

Como tercer requisito, para cada mensaje dentro del conjunto de mensajes si existe un tipo tal que $m^{*}\left(t_{j}\right)=m_{j}$ la conjetura del receptor en el conjunto de información correspondiente a $\mathrm{m}_{\mathrm{j}}$ debe derivarse de la regla de Bayes.

Tal como se ha indicado anteriormente, el juego consiste en dos participantes, una familia que puede optar por emprender a través de la madre o el padre y buscar financiamiento con una institución de crédito. Para el juego ilustrado en la Figura 2. Se busca ejemplificar en modo extensivo en primer lugar los tipos para la iniciativa empresarial de la familia, en donde dicha actividad puede generar flujos de efectivo favorables con una probabilidad de a y puede generar flujos de efectivo desfavorables con una probabilidad dada de $(\mathbf{1}-\boldsymbol{\alpha})$ de este modo, ejemplifica la probabilidad de obtener un tipo dado. Dichas probabilidades se ven definidas por los múltiples factores que inciden en que una pequeña empresa compita en su mercado.

El modelo también contempla el conjunto de mensajes para el emisor (familia) que puede optar por enviar el mensaje que la esposa puede solicitar el crédito con el tipo de flujos de efectivo favorables con una probabilidad dada de $\theta$ o bien que puede solicitar el crédito con un tipo de flujos de efectivo desfavorables con una probabilidad de $(1-\theta)$. Por otro lado, la familia puede elegir enviar el mensaje que el padre es el contratante del crédito y quien ejercerá la actividad empresarial, considerando para el mismo caso, la probabilidad de $\sigma$ para un flujo de efectivo favorable en el negocio y una probabilidad de $(1-\sigma)$.

Velázquez Juárez, E. \& Urbiola Solís, A. 
Por último, el modelo también contempla las funciones de pagos dadas para cada una de las estrategias del receptor una vez recibido el conjunto de mensajes, en el cual se expresan en primer lugar los pagos para la familia y en segundo lugar los pagos de la institución de crédito. En este aspecto, la institución de crédito puede optar por un perfil de estrategias dado como $a_{1}$ : Otorgar el crédito y $a_{2}$ : No otorgar el crédito al solicitante. En este sentido, las funciones de pagos se desglosan en primer lugar mostrando los pagos de la familia y en segundo lugar los de la institución de crédito y será teniendo en cuenta lo siguiente:

Cuando la familia decide que la mujer emprenderá el negocio y solicitará el crédito sus garantías serán siempre menores a entregar que las del hombre por las condiciones expresadas por Cervantes (2005) y Vázquez y Hernández (2013). Por otro lado, para la institución de crédito que otorga el crédito para el hombre cuando es del tipo que no puede cubrir con los flujos de efectivo las amortizaciones, sus pagos estarán dados por la pérdida de su utilidad por intereses. Y por último, en caso que el hombre decida emprender la actividad empresarial, en su función de pagos se añade el salario de la madre según Sadik (1989) como actividad potencializadora de la familia.

Figura 2. Modelo dinámico con información incompleta en forma extendida

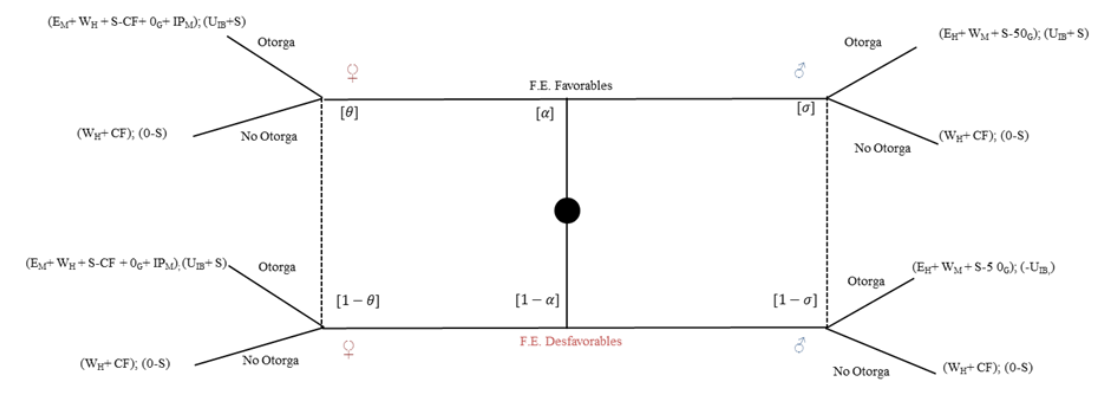

Fuente: Elaboración propia.

Con el propósito de simplificar la esquematización de los pagos y asignarles una jerarquización más precisa, para cada una de las estrategias del receptor, se asignarán valores cuantitativos definidos que se encuentran en función de los supuestos y consideraciones planteadas con anterioridad. Cabe mencionar que los valores entregados son meramente arbitrarios y que

\section{Decisiones familiares y teoría de juegos}


son propuestos con la finalidad de simplificar las funciones de pagos, es importante aclarar que, para lograr un mayor grado de explicación a través de este modelo, requeriría de recopilación de información empírica con el objeto de alcanzar mayor precisión en los datos, sin embargo, no se encuentra planteado dentro de los alcances de este trabajo. De esta manera, es que en la Tabla 1. Se establece un concentrado de las relaciones de magnitud entre variables y la ponderación propuesta con la finalidad de plantear el juego con supuestos específicos.

Tabla 1. Concentrado de relación de magnitudes ente variables y su ponderación numérica

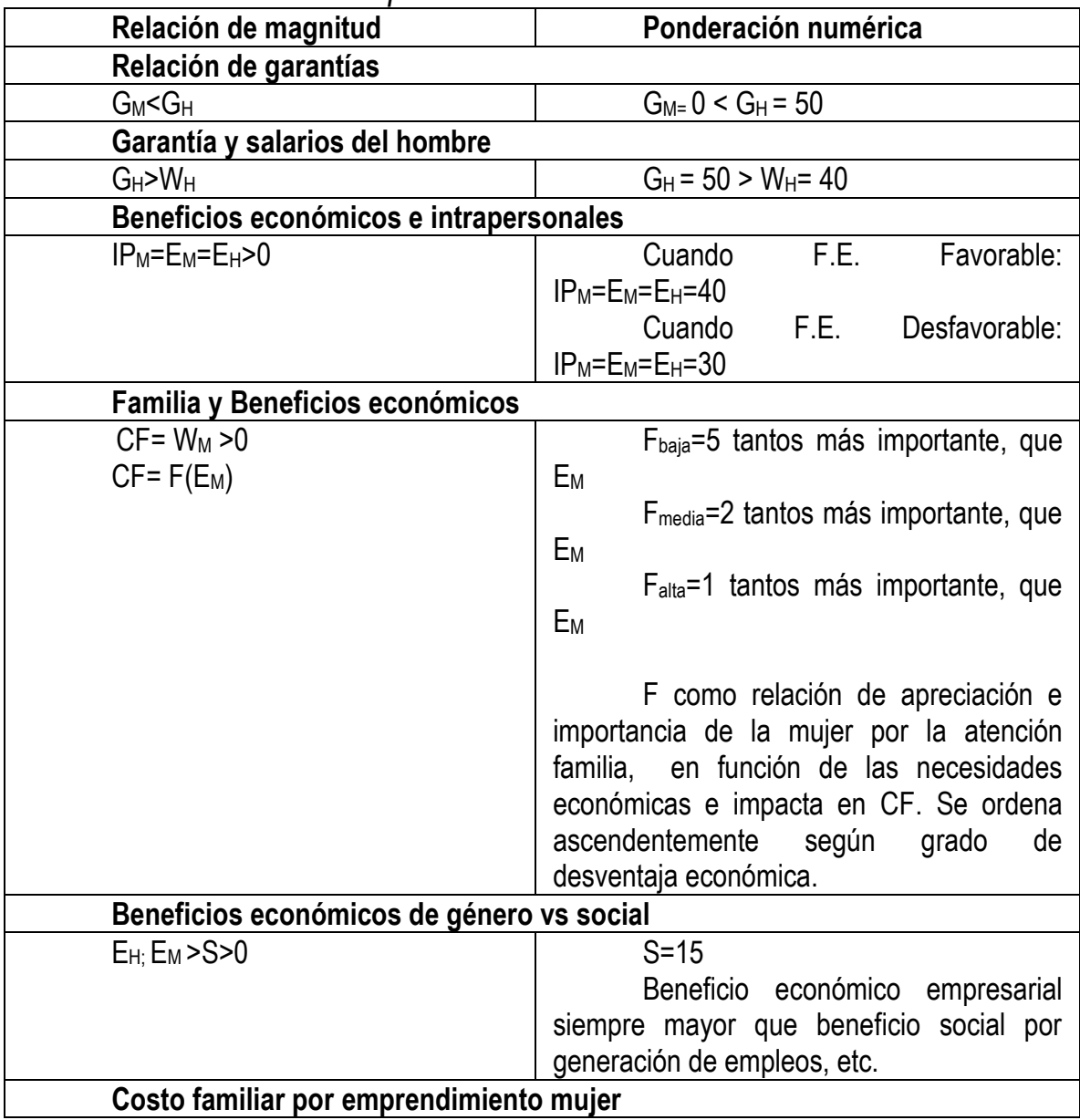

Velázquez Juárez, E. \& Urbiola Solís, A. 


\begin{tabular}{|c|c|}
\hline$C F=F\left(E_{M}\right)$ & $C F=200,80,40$. \\
\hline \multicolumn{2}{|c|}{ Utilidad de la institución crediticia } \\
\hline $\mathrm{U}_{\mathrm{IB}}=9_{\mathrm{M}} \% ; 22 \mathrm{H}_{\mathrm{H}} \%\left(\mathrm{E}_{\mathrm{M}} ; \mathrm{EH}_{\mathrm{H}}\right)>0$ & $\begin{array}{l}\mathrm{U}_{\mathrm{IB}}=3.6 ; 8.8 \\
\mathrm{Se} \text { selecciona como tasa } \\
\text { preferencial para la mujer en } 9 \% \text { según } \\
\text { (Secretaría de Economía, 2017). } \\
\text { Mientras que para el hombre se } \\
\text { selecciona tasa de mercado de } 22 \%\end{array}$ \\
\hline
\end{tabular}

Fuente: elaboración propia con datos de Secretaría de Economía (2017).

A partir de la numerización de las variables y supuestos considerados para el modelo se obtiene a figura 3. En su forma extensiva, que permite apreciar con mayor fidelidad las funciones de pagos para el juego. En la figura 3. Se expresan las funciones de pagos considerando que se tiene un $\mathrm{F}$ con condiciones de desventaja económica baja.

Figura 3. Modelo dinámico con información incompleta en forma extendida y simplificado

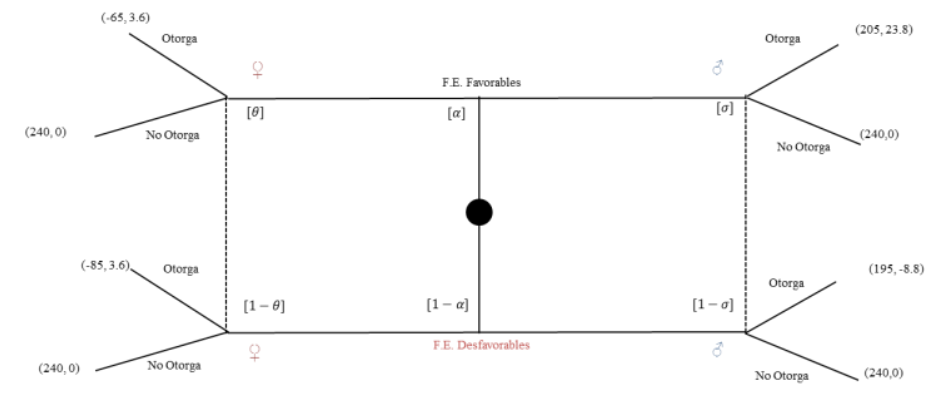

Fuente: Elaboración propia.

Para llevar a cabo la solución al modelo se ejecutará encontrando los equilibrios de agrupación y separación, con el cual se buscará explicar con sus debidos alcances el proceso de emprendimiento y acceso al crédito desde una perspectiva de género, con la finalidad de poder indicar a través de los equilibrios para qué género es el más favorable dar inicio a una actividad empresarial, de acuerdo con los supuestos planteados. Para el caso específico de este juego, se contempla a una familia en donde las condiciones económicas no son de extrema urgencia para la madre, por lo que tiene un $\mathrm{F}$

\section{Decisiones familiares y teoría de juegos}


bajo, por otro lado, contempla los mismos beneficios económicos en la actividad empresarial para el hombre y la mujer.

Tabla 2. Determinación de equilibrios bayesianos con un $F_{b a j o \text {. }}$

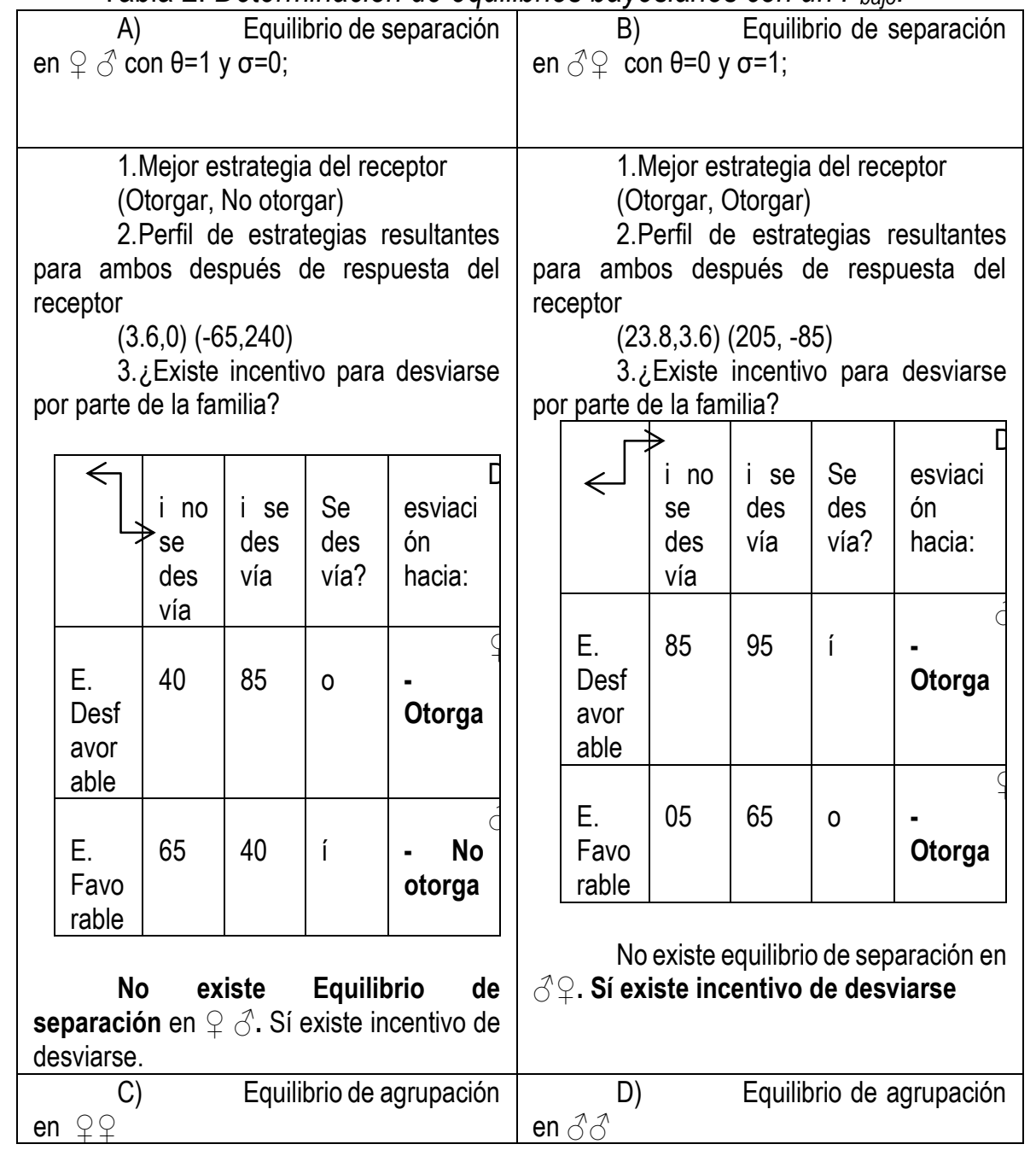

Velázquez Juárez, E. \& Urbiola Solís, A. 


\begin{tabular}{|c|c|c|c|c|c|c|c|c|}
\hline \multicolumn{5}{|c|}{$\begin{array}{l}\text { 1.Actualización de conjeturas con } \\
\text { un a de } 0.5 \\
\text { 2. Decisión del receptor en la } \\
\text { trayectoria de equilibrio } \\
\mathrm{Si} \text { elige otorgar: } \frac{1}{2}(18.6)+ \\
\frac{1}{2}(18.6)=183.6 \\
\mathrm{Si} \text { elige no otorgar: } \frac{1}{2}(-15)+ \\
\frac{1}{2}(-15)=-15 \\
\text { El banco elegirá siempre otorgar ya } \\
\text { que 3.6>-15 } \\
\text { 3. ¿Existe incentivo de desviarse? }\end{array}$} & \multicolumn{4}{|c|}{$\begin{array}{l}\text { 1.Actualización de conjeturas con un } \\
\text { a de } 0.5 \\
\text { 2.Decisión del receptor en la } \\
\text { trayectoria de equilibrio } \\
\mathrm{Si} \text { elige otorgar: } \frac{1}{2}(23.8)+ \\
\frac{1}{2}(-8.8)=7.5 \\
\mathrm{Si} \text { elige no otorgar: } \frac{1}{2}(-15)+ \\
\frac{1}{2}(-15)=-15 \\
\text { El banco elegirá siempre otorgar ya } \\
\text { que } 7.5>-15 \\
3 . \text { ¿Existe incentivo de desviarse? }\end{array}$} \\
\hline & \multirow[t]{2}{*}{$\begin{array}{l}\text { i no } \\
\text { se } \\
\text { des } \\
\text { vía }\end{array}$} & \multirow[t]{2}{*}{$\begin{array}{l}\text { i se } \\
\text { des } \\
\text { vía } \\
\hat{0}- \\
\text { Otor } \\
\text { ga }\end{array}$} & \multirow{2}{*}{$\begin{array}{l}\text { e } \\
\text { des } \\
\text { vía } \\
\text { o- } \\
\text { No } \\
\text { otor } \\
\text { ga }\end{array}$} & $\begin{array}{l}\text { esviaci } \\
\text { ón } \\
\text { hacia: }\end{array}$ & & $\begin{array}{l}\text { ino se } \\
\text { desví } \\
\text { a }\end{array}$ & $\begin{array}{l}\text { i se } \\
\text { desví } \\
\text { a O.- } \\
\text { Otor } \\
\text { ga }\end{array}$ & $\begin{array}{l}\text { D } \\
\text { esviación } \\
\text { hacia: }\end{array}$ \\
\hline & & & & & $\begin{array}{l}\text { E. } \\
\text { Desfav } \\
\text { orable }\end{array}$ & 95 & 65 & \\
\hline $\begin{array}{l}\text { Desf } \\
\text { avor } \\
\text { able }\end{array}$ & & & & & $\begin{array}{l}\text { E. } \\
\text { Favora } \\
\text { ble }\end{array}$ & 05 & 75 & 0 \\
\hline $\begin{array}{l}\text { E. } \\
\text { Favo } \\
\text { rable } \\
\end{array}$ & 75 & 05 & 40 & $\begin{array}{l}\text { I en } \begin{array}{l}\hat{*} \\
\text { No } \\
\text { otorga }\end{array} \\
\end{array}$ & \multicolumn{4}{|c|}{$\begin{array}{l}\text { Sí existe equilibrio de agrupación. } \\
\text { No existe incentivo de desviarse hacia } \\
\text { que la mujer no emprenda, dado que las } \\
\text { estrategias dominantes del receptor } \\
\text { siempre lo impiden y tampoco al } \\
\text { emprendimiento femenino dadas las } \\
\text { funciones de pago. }\end{array}$} \\
\hline
\end{tabular}

Decisiones familiares y teoría de juegos 
4.Puntos Críticos

Si el banco elige no otorgar, fuera de la trayectoria de equilibrio:

$$
240(\theta)+240(1-\theta)=240 \theta-240 \theta+240=240
$$

Si el banco elige otorgar, fuera de la trayectoria de equilibrio:

Entonces:

$$
-65(\theta)-85(1-\theta)=-65 \theta+85 \theta-85=20 \theta-85
$$

$20 \theta-85>240$

$20 \theta>325$

$\theta>325 / 10$

Fuente: Elaboración propia.

De la tabla 2. Es importante mencionar que no existieron equilibrios de separación, pero sí en agrupación para el emprendimiento masculino, en otras palabras, para este juego fue posible encontrar el momento en el que las estrategias sean mutuamente eficientes para ambos jugadores maximizando sus ganancias de acuerdo con las especificaciones para que se presente un equilibrio bayesiano perfecto, específicamente en aquel que permite discernir entre emprender a través del hombre o la mujer, definiendo que es más eficiente para una familia con $\mathrm{F}$ con necesidad económica baja y con prioridad alta hacia los otros miembros de la familia en el papel de potencialización de capacidades a través del papel de la madre, según Sadik (1989).

Es importante mencionar que para el equilibrio de separación A) existen incentivos de desviarse de optar por el emprendimiento de la mujer con iniciativa empresarial con flujos de efectivo favorables y es preferible para la familia que la madre no emprenda y que el padre sea quien en sustitución busque un empleo y la madre sea quien asuma los pagos obtenidos por la potencialización de la familia, considerado como un supuesto fuerte. Mientras que en el equilibrio de separación B) existe también un incentivo de desviarse si el proyecto de familia con F.E. desfavorables pues los pagos en el emprendimiento masculino son mayores por efecto de CF. En adición, para el equilibrio de agrupación en C) también existe incentivo de desviarse, pues es preferible para la función de pagos familiar que el hombre sea quien asuma la responsabilidad de proveedor familiar y que la familia obtenga pagos por

\section{Velázquez Juárez, E. \& Urbiola Solís, A.}


salarios combinados. Por último, el equilibrio de agrupación $\mathrm{D}$ ) también indica que si existe un equilibrio de agrupación y que para la familia resulta más favorable que el hombre sea quien emprenda, sin importar si es a través de un negocio que entregue F.E. favorables o desfavorables, pues las funciones de utilidad se inclinan a que existe igualdad de condiciones para generar ingresos, pero la mujer es quien se ve biológicamente y socialmente forzada a castigarlos dada la necesidad de atención familiar.

Cabe mencionar, que para el juego elegido, puede parecer tendenciosa la postura a que la mujer no emprenda y es necesario aclarar en este punto que la ausencia de equilibrios bayesianos perfectos puede variar de acuerdo con las condiciones específicas de la familia analizada, así siendo posible que los equilibrios bayesianos varíen de acuerdo a su aplicación en condiciones específicas de ingresos por trabajo masculino (en caso de que exista) y femenino, diferencia en los ingresos económicos por las actividades empresariales de acuerdo con el género, el grado de dependencia familiar de los miembros de la familia con la madre (que afecta a CF) entre otros aspectos específicos que el modelo no contempla, tales como la probabilidad de obtener flujos de efectivo favorables o desfavorables, que a su vez éstos dependen de aspectos macroeconómicos y microeconómicos, tales como las características particulares de la iniciativa empresarial y la administración de la misma para poder definir con mayor precisión los resultados.

Para ejemplificar un abanico más amplio de análisis del modelo, se sugerirá un segundo escenario que contemple condiciones de mayor adversidad para la familia, de tal manera que las funciones de pagos sean alteradas y de tal manera entender el grado de influencia de las variables CF, $E_{M}$ y $W_{H}$ en el planteamiento de ciertos equilibrios.

Para el caso específico de la Figura 4. Se considerará una familia en la que uno de los supuestos de mayor relevancia es que el hombre no tiene un empleo o que lo llega a tener en condiciones de mala remuneración, colocando a la mujer en un escenario que le incentivan a iniciar la actividad empresarial a fin de cubrir con los ingresos que deja de proveer el padre. A partir de lo anterior es que la variable de $W_{H}=0$, respecto de la influencia de $C F$, se tiene que contemplar que se tiene una alta exigencia económica familiar por lo que se obtiene un $F_{\text {alto }}$ y por otro lado, las variables de garantías, pagos para el banco y probabilidades se mantienen constantes respecto de los supuestos

\section{Decisiones familiares y teoría de juegos}


planteados en el caso anterior. De esta manera los pagos se constituyen de acuerdo con la Figura 4.

Figura 4. Modelo dinámico con información incompleta en forma extendida y simplificado

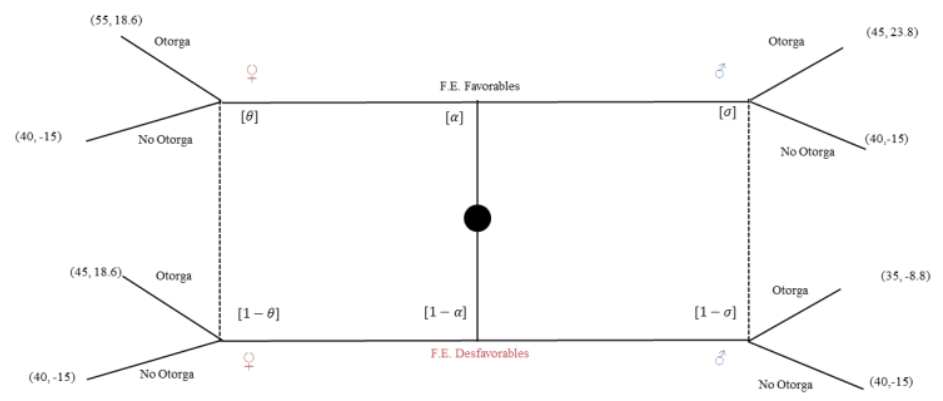

Fuente: Elaboración propia.

A continuación, en la tabla 3 . Se buscará determinar los equilibrios bayesianos perfectos para el juego, del mismo modo, en la parte superior se pueden identificar los equilibrios de separación y en la parte inferior los equilibrios de agrupación.

Tabla 3. Determinación de equilibrios bayesianos con un $F_{\text {alto. }}$

\begin{tabular}{|c|c|c|c|c|c|c|c|c|}
\hline \multicolumn{4}{|c|}{$\begin{array}{l}\text { E) } \quad \text { Equilibrio de separación } \\
\text { en }+\hat{\sigma} \operatorname{con} \theta=1 \text { y } \sigma=0 ;\end{array}$} & \multicolumn{5}{|c|}{$\begin{array}{l}\text { F) } \\
\text { en } \sigma^{\lambda} \circ \operatorname{con} \theta=0 \text { y } \sigma=1 ;\end{array}$} \\
\hline \multicolumn{4}{|c|}{$\begin{array}{l}\text { 1.Mejor estrategia del receptor } \\
\text { (Otorgar, No otorgar) } \\
\text { 2.Perfil de estrategias resultantes } \\
\text { para ambos después de respuesta del } \\
\text { receptor } \\
\quad(18.6,-15)(55,40) \\
\text { 3. ¿Existe incentivo para desviarse } \\
\text { por parte de la familia? }\end{array}$} & \multicolumn{5}{|c|}{$\begin{array}{l}\text { 1.Mejor estrategia del receptor } \\
\text { (Otorgar, Otorgar) } \\
\text { 2.Perfil de estrategias resultantes } \\
\text { para ambos después de respuesta de } \\
\text { receptor } \\
\quad(23.8,18.6)(45,45) \\
\text { 3. ¿Existe incentivo para desviarse } \\
\text { por parte de la familia? }\end{array}$} \\
\hline $\begin{array}{l}\text { i no } \\
\text { se }\end{array}$ & $\begin{array}{l}\text { i se } \\
\text { des } \\
\text { vía }\end{array}$ & $\begin{array}{l}\text { Se } \\
\text { desv } \\
\text { ía? }\end{array}$ & iaci & $\leftarrow$ & $\begin{array}{l}\text { i no } \\
\text { se } \\
\text { des } \\
\text { vía }\end{array}$ & $\begin{array}{l}\text { i se } \\
\text { des } \\
\text { vía }\end{array}$ & $\begin{array}{l}\text { Se } \\
\text { desv } \\
\text { ía? }\end{array}$ & $\begin{array}{l}\text { esviaci } \\
\text { ón } \\
\text { hacia: }\end{array}$ \\
\hline
\end{tabular}

\section{Velázquez Juárez, E. \& Urbiola Solís, A.}




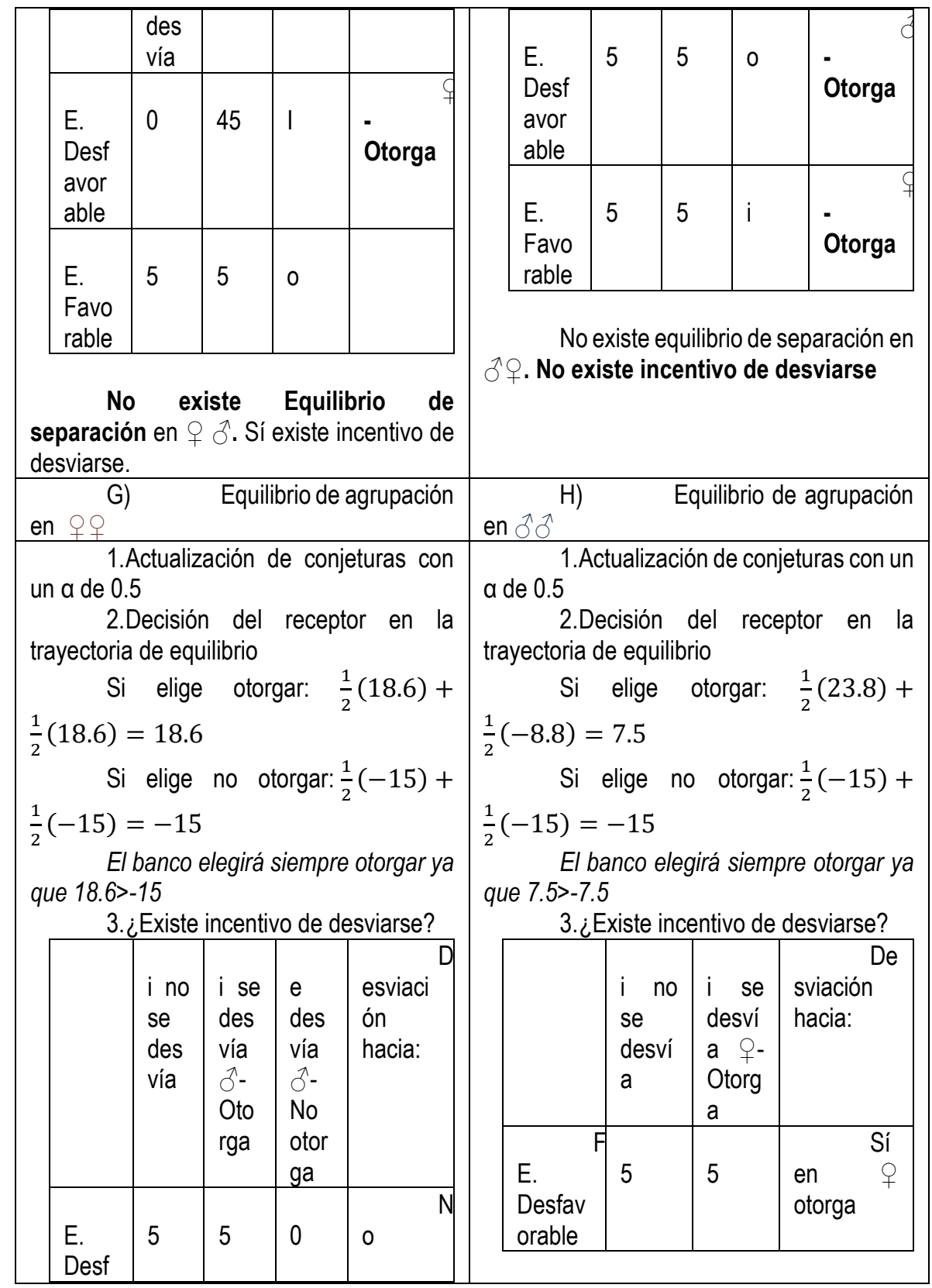

\section{Decisiones familiares y teoría de juegos}




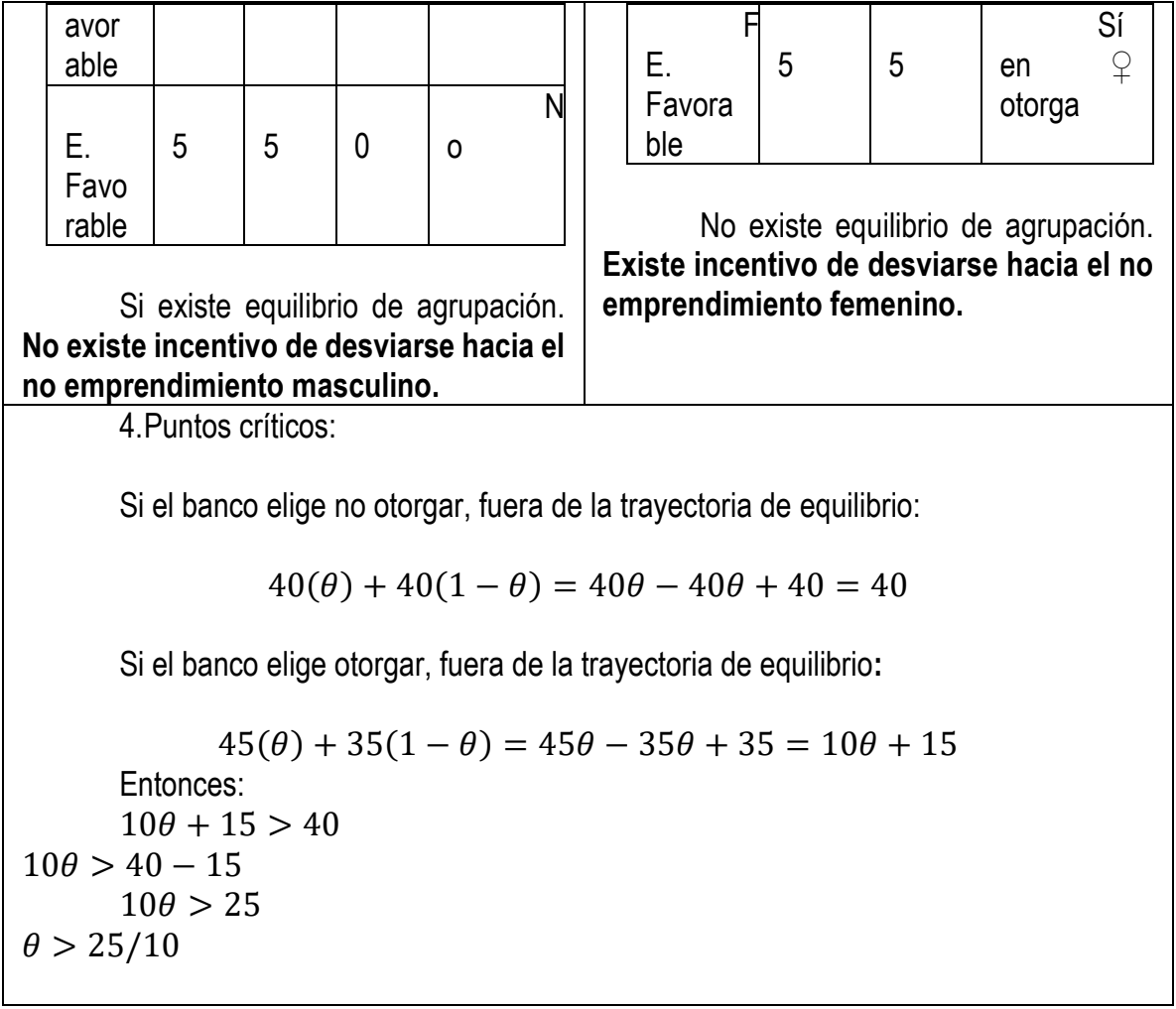

Fuente: Elaboración propia.

De la Tabla 3. Es necesario resaltar que solamente existió equilibrio de agrupación en G) mientras que en los demás equilibrios siempre existieron incentivos de desviarse. Respecto del equilibrio de agrupación en $+ㅜ$ se puede conocer que las estrategias resultan mutuamente eficientes tanto para el emisor como para el receptor, en el sentido que tanto la institución de crédito logra maximizar sus funciones de utilidad, como la familia no encuentra incentivos de desviarse respecto de posturas diferentes dado un mensaje alterno al receptor. De esta manera, considerando una familia con un $\mathrm{F}$ alto, 0 en otras palabras con una necesidad económica elevada, es eficiente que sin importar el tipo sea la mujer quien emprenda la actividad. De esta última premisa, es posible determinar lo siguiente: 
- Es preferible que en condiciones de necesidad económica alta la mujer emprenda, ya que los beneficios obtenidos por la actividad empresarial tienen el mismo potencial sin importar quien emprenda. Considerando las restricciones de garantías, resulta tanto más eficiente como menos riesgoso con respecto a las funciones de pagos, permitiendo de esta manera evitar entregar garantías de algún tipo a la institución de crédito y al mismo tiempo obtener los beneficios del emprendimiento. Por otro lado, es necesario considerar que, en las funciones de pagos, se encuentra fuertemente influenciando el salario masculino $W_{H}$ que no aporta nada a la función de pagos, de tal manera que cuando el hombre decide emprender, no existe incentivo para la familia de desviarse considerando que los beneficios globales son mayores y que se pueden percibir sumados beneficios intrapersonales para la mujer con el costo familiar inherente.

Por otro lado, fuera de la trayectoria de equilibrio, siempre existe un incentivo de desviarse implicando un mensaje diferente al que corresponde dentro de la trayectoria de equilibrio, así que no representa un equilibrio bayesiano perfecto en donde los participantes logren maximizar sus funciones de utilidad.

Hasta este punto, concluye la conformación del juego modelado y las dos posibles simulaciones que en él se generaron, ambas considerando dos escenarios antagónicos y con condiciones de adversidad y prosperidad familiar y económica. En este momento, es pertinente aclarar que pese a que existen un sinnúmero de escenarios posibles que puedan ser insertos en el modelo propuesto en este trabajo, es de suma importancia realizar un contacto empírico que permita aproximarse a una explicación aún más vinculada, que se conforme de supuestos no solamente teóricos sino respaldados en su valoración por las percepciones empíricas de las familias 0 de los emprendedores y emprendedoras.

Por último, una de las consideraciones de este modelo, es que hasta este punto se logró explicar con base en el marco teórico ciertos elementos, como la interacción entre los participantes del juego, la influencia de las funciones de pagos en los equilibrios, el grado de impacto cuando se altera una 0 más variables respecto de las funciones de pagos dadas y por consecuencia en los equilibrios y por último, el difícil papel que juega una mujer al momento de decidir emprender cuando tiene una familia y cierto grado de

\section{Decisiones familiares y teoría de juegos}


dependencia por el(los) integrante(s) que la conforman, ya que se le es conferida una responsabilidad biológica y social que difícilmente congenia con la actividad empresarial, poniéndola en una difícil decisión entre la familia y la actividad empresarial. Más adelante, en las conclusiones se abordarán propuestas de investigación futura en este último aspecto.

\section{Discusión}

En conclusión, este logra establecer un vínculo del tipo explicito entre las decisiones familiares del emprendimiento y el género gracias al planteamiento y desarrollo de incentivos y pagos para dos escenarios antagónicos en un modelo de señalización con información incompleta. Para el escenario planteado en el que se encuentra una familia nuclear de una madre, un padre e hijos, con una baja necesidad económica por generar flujos adicionales de efectivo y con un costo familiar alto en emprendimiento femenino, no existen equilibrios de separación, pero solamente existe uno de agrupación en hombre-hombre en el cual se maximizan las utilidades para cada uno de los participantes del juego, incentivando siempre a que el hombre sea quien lleve a cabo la actividad de proveedor de familia, pues los costos familiares tienen una carga fuerte que es difícil de ser sustituida o mitigada, en el supuesto de que la madre pueda ser emprendedora sin que esto implique descuidar la posición familiar dado el tiempo y los esfuerzos que un negocio puede demandar. Como una de las conclusiones de este estudio, es analizar la posibilidad de comprobar a través de un estudio empírico las especificidades de las diferencias de género existentes para este modelo.

Se pueden establecer ciertas concordancias entre los equilibrios de separación dados en el juego y las aportaciones del Banco Mundial (2010) considerando los elementos que incentivan o desincentivan el emprendimiento femenino, dado en primer lugar por la riqueza familiar que se establece en el primer escenario y en un segundo lugar, con los costos familiares expresados en el modelo, que contempla las aportaciones de Pérez (2012) considerando los aspectos que han dado lugar a las condiciones desventajosas y precarias en el mercado laboral para el género femenino. Mientras que, en una segunda instancia, se contemplan las aportaciones de Rendón (2004) quien enuncia que existen limitaciones de carácter social y de género en el rol de empresaria

Velázquez Juárez, E. \& Urbiola Solís, A. 
y cuando se trata de una mujer con un desarrollo familiar más complejo que involucre matrimonio e hijos, debe ella también cumplir con ambos roles, especificando los costos familiares que inciden fuertemente en las funciones de utilidad que el modelo especifica.

Como segunda conclusión en este trabajo, se obtuvo que proponiendo un segundo escenario en el que la familia se encontrase en condiciones de mayor adversidad mediante la modificación de variables tales como el costo familiar, los salarios del hombre y manteniendo constante los demás elementos, se obtuvo que existe un equilibrio de agrupación mujer-mujer, en el cual maximizan los participantes sus utilidades y no tienen incentivos de desviarse. En este equilibrio, la familia optará por emprender a través de la madre, sin importar el tipo que se trate, pues implica una menor exposición al riesgo para sus garantías, un costo familiar inherente, pero al contar con mayor necesidad económica familiar, deja en manifiesto las aseveraciones del Banco Mundial (2010) respecto de los motivantes del emprendimiento femenino, en las que se denota una mayor posibilidad de emprendimiento dadas las condiciones económicas desfavorables a partir de un factor de inducción dadas las escasas oportunidades de empleo, salarios precarios y la posibilidad de lograr el autoempleo como vía de flexibilización y respuesta ante periodos de escasez.

Tal y como ha sido señalado en los resultados, una de las consideraciones importantes para este estudio, es que a través del modelado inicial del juego sea posible extrapolarlo a diferentes escenarios con la intención de analizar las interacciones entre los jugadores y en una segunda instancia entender y explicar escenarios diferentes y aún más específicos. Como una de las alternativas para este estudio se propone estudiar el emprendimiento femenino cuando no existe una relación familiar que le pueda generar desutilidad que genera CF en sus funciones de pago, pero que a su vez pueden existir otros conceptos por los que se genere desutilidad con sus respectivas proporciones. También, el modelo propuesto en este trabajo puede ser sometido a actividades empresariales que impliquen la agrupación de dos o más madres de diferentes familias que bajo el esquema de agrupación decidan llevar a cabo una agrupación empresarial, para que en el conjunto de esfuerzos empresariales se puedan maximizar los beneficios, inclusive más

\section{Decisiones familiares y teoría de juegos}


allá contra los salarios que pueda obtener el hombre y minimizando los costos familiares dada la distribución de responsabilidades empresariales.

Este trabajo da puerta abierta a entender sistémicamente este fenómeno, pues es notorio que la desigualdad de género es notoria pues a la madre se le confiere una responsabilidad desde el punto de vista biológico y social, que le pone en una condición de decisión muy difícil. Para este aspecto, es importante considerar que desde las políticas públicas es posible establecer propuestas con la finalidad de reducir la brecha y permitir que la mujer emprenda, y de esta manera aproveche todos los elementos adicionales en su función de pagos, como el empoderamiento, el desarrollo social e intrapersonal, entre muchos otros. Por último, este trabajo recupera valor y originalidad en los estudios de pequeñas empresas presentando una explicación breve del proceso de decisiones familiares en el emprendimiento desde la teoría de juegos, considerando sus alcances dados los supuestos fuertes que en él se establecen, dando pie a generar así modelos aún más complejos que consideren una mayor cantidad de variables o modos de interpretar la realidad.

\section{Referencias}

Ariza, M., \& De Oliveira, O. (2004). Unión conyugal e interrupcion de la trayectoria laboral de las trabajadoras urbanas en México. En Cambio Demográfico y social en el México del siglo XX. El Colegio de la Frontera Norte.

Banco Mundial. (2010). Mujeres empresarias. http://siteresources.worldbank.org/INTLACREGTOPPOVANA/Resources/8404421260809819258/Libro_Mujeres_Empresarias.pdf

Banco Mundial. (2019). Crecimiento anual PIB México. https://datos.bancomundial.org/indicador/NY.GDP.MKTP.KD.ZG?end=1994\&location $s=M X \&$ start=1961\&view=chart

Burin, M. (2012). Masculinidades y femineidades: Identidades laborales en crisis. En En La Crisis del Patriarcado (editado por Mabel Burin, Irene Meler, Débora Tajer, Juan Carlos Volnovich y César Hazaki, pp. 63-78). Topia Editorial.

Burin, M., \& Meler, I. (2010). Género y Familia. Poder, amor y sexualidad en la construcción de la subjetividad. Paidós.

CEPAL. (2004). Acceso al crédito de las mujeres en América Latina. http://www.cepal.org/mujer/proyectos/gtz/publicaciones/word_doc/Muriel_Zuniga.pdf

Cervantes, E. (2005). El Microfinanciamiento como un Esfuerzo de la Sociedad Civil para Generar Desarrollo. Un Análisis sobre el Papel del Gobierno-Edición Única [ITESM]. http://hdl.handle.net/11285/573053

Velázquez Juárez, E. \& Urbiola Solís, A. 
CONDUSEF. (s/f). Crédito para ellas.

De la O, M., \& Guadarrama, R. (2006). Género, proceso de trabajo y flexibilidad laboral en América Latina. En Teorías Sociales y Estudios de trabajo: Nuevos enfoques. Anthropos/Universidad Autónoma Metropolitana.

De la Rosa, A., Rivera, A., \& Marín, A. (2015). Propuesta de clasificación integral de la Mipyme basada en la complementariedad disciplinar de las perspectivas económica, administrativa y organizacional. En La MiPyme a Debate. Gasca.

Gibbons, R. (1994). Un primer curso de teoría de juegos. AntoniBosch.

Lagarde, M. (1996). Género y feminismo. Desarrollo humano y democracia. Horas y Horas.

Mayoux, L. (2000). Microfinanciamiento para el empoderamiento de las mujeres: Un enfoque de aprendizaje, gestión y acción participativos.

Organización Internacional del Trabajo. (2001). Programa Modular de Capacitación e Información sobre género, pobreza y empleo en Chile. Módulo 4: Recursos Financieros para los pobres: El Crédito".

Pérez, F. (2012). Desigualdades de género en el inicio de la vida laboral estable. 213-246.

Rendón, T. (2004). El mercado laboral y la división intrafamiliar del trabajo. En Imágenes de la familia en el cambio de siglo. Universo familiar y procesos de trabajo contemporáneos. UNAM.

Rendón, T., \& Salas, C. (2000). La evolución del empleo. En Trabajo y trabajadores en el México contemporáneo,. Miguel Ángel Porrúa.

Rubin, G. (1986). El tráfico de mujeres: Notas sobre la "economía política" del sexo. Revista Nueva Antropología VIII (030), 95-145.

Rubin, G. (2013). El tráfico de mujeres: Notas sobre la 'economía política' del sexo. En En Marta Lamas (compiladora) El género: La construcción cultural de la diferencia sexual. PUEG.

Saavedra, L., Tapia, B., \& Aguilar, M. (2014). El problema de Financiamiento de la PYME. https://www.google.com.mx/url?sa=t\&rct=j\&q=\&esrc=s\&source=web\&cd=1\&cad=rja\& uact=8\&ved=0ahUKEwjM4rbxklrUAhUIWSYKHXMJC50QFggoMAA\&url=http $\% 3 A \% 2$ F\%2Fwww.alafec.unam.mx\%2Fdocs\%2Fasambleas\%2Fxiv\%2Fponencias\%2F4.01.p df\&usg=AFQjCNHxQx6SZOydlTedivwbTAUC1PxMeg\&sig2=9sxMU8PGRiWRvchPn $\mathrm{SsO} \mathrm{AA}$

Sadik, N. (1989). Estado de la Población Mundial. Fondo de Población de las Naciones Unidas.

Secretaría de Economía. (2017). Conoce el Programa Mujeres Pyme. http://www.gob.mx/se/articulos/conoce-el-programa-mujeres-pyme

Vázquez, V., \& Hernández, J. (2013). Matriz de probabilidad de transición de microcréditos: El caso de una microfinanciera mexicana. 28, 39-77.

Yurén, T. (2004). La filosofía de la educación en México. Principios, fines y valores. Trillas.

\section{Decisiones familiares y teoría de juegos}

